\title{
El catolicismo social en la Semana Trágica de Buenos Aires (1919)
}

\author{
Social Catholics in Buenos Aires' Tragic Week (1919)
}

\author{
Sabrina E. Asquini \\ sabrina.asquini@gmail.com \\ Universidad de Buenos Aires / CONICET, Argentina
}

Recepción: 30 Septiembre 2019

Aprobación: 07 Abril 2020

Publicación: 13 Noviembre 2020

Cita sugerida: Asquini, S. E. (2020). El catolicismo social en la Semana Trágica de Buenos Aires (1919). Anuario del Instituto de Historia Argentina, 20(2), e126. https://doi.org/10.24215/2314257Xe126
Resumen: La Semana Trágica de enero de 1919 catalizó distintas tendencias sociales presentes en la ciudad de Buenos Aires durante la inmediata posguerra. En un contexto de polarización política, la Iglesia Católica y el catolicismo asumieron un rol activo en la defensa del orden. En el artículo se analizan las perspectivas con que el catolicismo social porteño -especialmente aquel organizado en torno a los Círculos de Obreros (1892) - intervino en la coyuntura del final de la I Guerra Mundial, qué posición tomaron en relación a la violencia estatal y paraestatal durante la huelga general, y qué tipo de iniciativas promovieron en lo sucesivo.

Palabras clave: Semana Trágica, Iglesia Católica, catolicismo, conflictividad obrera.

\begin{abstract}
The Tragic Week on January 1919 triggered different social tendencies which were acting in Buenos Aires during the first postwar period. In a specific political polarization context, the Catholic Church and Catholicism took on an active role in order to defend the social order. Particularly, this article analyses the perspectives with which Social Catholicism of Buenos Aires -especially the one organized by Workers Circles (1892)- acted during the late First World War, which was the attitude towards state and non-state violence used in the general strike and what kinds of initiatives they promoted thereafter.
\end{abstract}

Keywords: The Tragic Week of Buenos Aires, The Catholic Church, Catholicism, Worker unrest.

A poco tiempo de haber concluido la Primera Guerra mundial, estalló en Buenos Aires una huelga general de características insurreccionales, que rebasó el ámbito laboral, tomó calles y paralizó la ciudad. ${ }^{1}$ La elite política seguía atentamente el recorrido del proceso revolucionario ruso, en medio de un clima de alerta internacional, que observaba con preocupación su repercusión en las filas obreras. En ese marco, el gobierno argentino respondió con una represión de vasto alcance. El ejército tomó el control de la ciudad y su acción represiva fue acompañada por la actuación de grupos civiles. La cifra de muertos y heridos es aún hoy, a cien años de distancia, incierta. Estamos hablando de la Semana Trágica de Buenos Aires, ocurrida entre el 7 y el 17 de enero de 1919. Este episodio ha sido un tópico muy transitado por la historiografía argentina (Babini, 1956; Godio, 1972; Rock, 2010; Bilsky, 2011; Lvovich, 2003; Silva, 2011; Lvovich, 2016; Díaz, 2019; entre 
otros), ya que marcó una inflexión en la dinámica del movimiento obrero y agrupó a las distintas facciones de la clase dominante detrás de un tipo de acción represiva poco visto hasta entonces.

La huelga en los talleres Vasena, una de las empresas metalúrgicas más grande del subcontinente, se había iniciado en los primeros días de diciembre de 1918. El reclamo de los trabajadores buscaba recomponer las condiciones de trabajo que habían sido fuertemente afectadas por la guerra. ${ }^{2}$ Por su parte, la patronal, que se mantenía inflexible ante las demandas obreras, había recurrido a la contratación de rompehuelgas y a vigilancia propia, a lo cual se sumó la asignación de efectivos policiales regulares. Al mes de iniciado el conflicto, la situación en la puerta de los talleres había alcanzado ya un importante nivel de tensión, y en los primeros días de enero hubo varios choques entre los huelguistas y las fuerzas de seguridad. El día 6 falleció un cabo de la policía; ${ }^{3}$ algunas versiones sugieren que los hechos del día 7 , ocurridos por la tarde, deben ser vistos como una revancha policial. El tiroteo duró varias horas; murieron cuatro trabajadores y hubo al menos una veintena de heridos. ${ }^{4}$ Este episodio fue respondido con un acto de clara solidaridad: una manifestación multitudinaria se acercó a los espacios fijados para el velatorio de las víctimas. Un cortejo fúnebre acompañó el día 9 hacia el Cementerio del Oeste -Chacarita- los restos de los caídos del día martes 7 . A su paso, la gran columna atravesó distintos incidentes que más adelante describiremos, y en el cementerio fue reprimida.

La huelga general fue declarada el día 10 por las dos centrales obreras que existían entonces: la FORA del quinto, como se conocía a la central anarquista, y la FORA IX, de hegemonía sindicalista revolucionaria. Mientras esta huelga se desarrollaba de manera contundente, la dirigencia de la FORA IX se reunió con el presidente Hipólito Irigoyen a fin de forzar la resolución del conflicto en Vasena, liberar a los presos y levantar la huelga general. A poco de declarada la medida, el Partido Socialista ya contemplaba su interrupción, y ese mismo día a medianoche sacó un comunicado que llamaba a concluir la huelga, señalando la desnaturalización del movimiento de protesta a causa de factores externos a la organización sindical. Aunque ese comunicado fue criticado por el Partido Socialista Argentino, dirigido por Alfredo Palacios, este también llamó a levantar la medida (Bilsky, 2011, pp. 138-139). El Partido Socialista Internacional, que se había declarado solidario con los obreros de los talleres Vasena desde un principio y había invitado a participar de la movilización del día 9, adhirió, no obstante, a la declaración de la FORA IX de levantar la huelga cuando esta lo propuso. Así, ni siquiera la fracción izquierdista recientemente separada del PS pudo darle un curso revolucionario a la huelga (Bilsky 2011, p. 159). Esa tarea quedó solo en manos de una fracción de los anarquistas, que contaban con una capacidad limitada para abordarla. Esto es importante en la medida en que las fuerzas conservadoras hicieron otra interpretación de lo que sucedía, y leyeron alarmadas los hechos como un conato de revolución maximalista.

Desde el catolicismo, por otra parte, la semana que se inició el 7 enero de 1919 se vivió como la concreción de una profecía largamente anunciada. El diario El Pueblo, vocero central del catolicismo argentino en ese período, reprochaba que se los hubiese tildado de alarmistas "a los que veíamos llegar los acontecimientos..." y exigía una actitud decidida de parte del gobierno, al que responsabilizaba por el exceso de tolerancia con el crimen y por la falta de prevención para defender los intereses y la vida de los ciudadanos. Debe recordarse que, desde fines del siglo XIX, los católicos consideraban que en Argentina existían condiciones para que se desarrollasen entre los trabajadores las corrientes socialista y anarquista, lo cual era experimentado como una amenaza para los valores cristianos. La publicación y circulación local de la encíclica Rerum Novarum (1891) había aportado un programa con el cual los católicos salieron a enfrentar en el terreno de las ideas y de la organización el avance de estas posiciones en la clase obrera. Para 1919, tal línea de acción llevaba, en la ciudad de Buenos Aires, varias décadas de trabajo. En este tiempo, el catolicismo se había dotado de un conjunto de asociaciones - como los círculos de obreros, los patronatos, las ligas, los centros de estudios, los sindicatos, etcétera-, que estaban vinculadas al movimiento católico general, y al trabajo del Arzobispado, de las principales congregaciones y de la prensa católica (Recalde, 1986; Auzá, 1987; Mallimaci, 1992; Di Stéfano y Zanatta, 2010; Martín, 2012; Mauro, 2010 y 2015; Gerdes, 2016; Lida, 2013 y 2015). No obstante, el resultado de estas iniciativas había sido desigual y, para muchos, limitado. 
En aquellas situaciones de marcada conflictividad social que se sucedieron desde principios del siglo en la ciudad, tanto la Iglesia Católica como el catolicismo social asumieron un rol activo en la defensa del orden social imperante. Así, por ejemplo, en la Semana Roja de 1909, la Junta Central de Gobierno de los Círculos de Obreros sacó un manifiesto en el cual se desligaba de toda participación en la manifestación del $1^{\circ}$ de Mayo. Afirmaba que dicha huelga era "completamente injustificada" en sus móviles y en su forma, ya que se había afectado la libertad de trabajo de los demás obreros, y que la voluntad de un grupo minoritario se había impuesto por la fuerza contra los trabajadores que pretendían continuar trabajando. ${ }^{6}$ La Junta tomó similar postura poco después, durante la huelga convocada en repudio al fusilamiento del pedagogo español Francisco Ferrer ${ }^{7}$, y lo mismo sucedió tras el atentado contra el jefe de policía Ramón Falcón y su secretario Juan Alberto Lartigau. ${ }^{8}$ En este último caso, el catolicismo porteño repudió el atentado y reivindicó a los funcionarios policiales. ${ }^{9}$ En esa coyuntura, en un acto improvisado en uno de los círculos de obreros, su presidente señaló que se imponía que

cada uno vigilara por la seguridad de todos, descubriendo á la policía, que vela por nuestra tranquilidad, cuantas noticias ó síntomas sospechosos adviertan en las personas que por su conducta, ó sus opiniones, ó sus afinidades con esos centros tenebrosos, puedan ser consideradas como peligrosas á la tranquilidad y al progreso de la patria argentina. ${ }^{10}$

Este trabajo se propone explorar cómo el catolicismo interpretó y actuó en los últimos años de la segunda década del siglo XX ante ciertos episodios que daban cuenta de un crecimiento de la movilización y la conflictividad obrera en la ciudad de Buenos Aires. En particular, se analizan aquí las perspectivas con que el catolicismo social porteño -especialmente aquel que se organizó en torno a los Círculos de Obreros (1892) - intervino en la coyuntura de la Semana Trágica; qué posiciones se tomaron en relación a la violencia desplegada por las fuerzas represivas estatales y paraestatales, y qué tipo de iniciativas se promovieron en lo sucesivo. En lo que respecta a fuentes documentales, se trabajará con prensa diaria católica, socialista y comercial. Además, se han consultado las actas de la Junta de Gobierno y del Consejo General de los Círculos de Obreros, y el boletín parroquial de Nuestra Sra. de la Merced.

\section{El diagnóstico}

Nos hemos espantado ante el cuadro que acaba de presentar Buenos Aires. Pero esto es sólo el comienzo de la tragedia. La Gran Bestia apenas ha asomado su inmundo hocico. Si la Sociedad no se defiende solidariamente, no pasará mucho tiempo sin que se abra un abismo bajo nuestras plantas. ${ }^{11}$

A mediados de enero, en la Revista Mariana -boletín de la parroquia de la Merced, ubicada en el microcentro porteño-, un editorial se preguntaba de dónde habían salido "los incendiarios y ladrones en número tan enorme, esas mujeres, jóvenes y viejas, con sendos revólveres y puñales, en sus manos; esa multitud de niños y jovencitos, que presidían las manifestaciones ácratas, y eran los primeros en arrojar piedras á los tranvías, automóviles y edificios". ${ }^{12}$ Se respondía que quienes habían participado del movimiento ya se tratase de hombres, mujeres, niños o jóvenes, extranjeros o nacionales- tenían casi sin excepción su domicilio en la capital. El artículo afirmaba la necesidad de reconocer que existía una "perversidad latente" en todas las clases sociales, un espíritu de "rebelión diabólica" que no respetaba a la autoridad ni a lo sagrado. “ $i$ Vivimos en un ambiente envenenado!”, sentenciaba. Al preguntarse por los responsables de tal situación no dudaba en adjudicar esa responsabilidad a “iCasi todos!”. Unos difundían la doctrina a través de libros, folletos y periódicos; otros corrompían al pueblo en los teatros y cines o enseñaban a los niños a "burlarse de la Religión, de la moral, de los sacerdotes y del mismo gobierno"; tampoco cooperaban -o lo hacían con mezquindad- en las obras sociales que podían contrarrestar la propaganda destructora. Eran muy pocos los que hablaban, escribían o tomaban una actitud enérgica de condena ante el proceder de los "amigos del desorden y desconcierto social". ${ }^{13}$ 
Algunos días más tarde, hacia fines de enero, Gustavo Franceschi analizó en profundidad y extensión las causas que habían originado aquel movimiento que conmovió Buenos Aires. ${ }^{14}$ El sacerdote reconocía en lo ocurrido la convergencia de causas múltiples, algunas inmediatas y otras remotas, y, en su opinión, la solución definitiva del problema solo se alcanzaría cuando todas estas razones fuesen suprimidas.

A partir de un argumento recurrente en el catolicismo social desde fines del siglo XIX, Franceschi explicaba que, como consecuencia de la disminución del sentido moral de las sociedades occidentales hecho que se observaba en todas las clases sociales- había aumentado el egoísmo. Dado que el incremento del bienestar propio era deseado incluso a costa del prójimo, esta tendencia al individualismo constituía un vicio disolvente y antisocial. A su vez, la incredulidad respecto de la existencia de otro mundo determinaba la necesidad de concretar en la vida presente todo deseo o goce, y sin una voz superior que premiara o guiase, difícilmente podría verificarse el sacrificio de renunciar a tal realización. Esta búsqueda de satisfacción permanente de los deseos materiales conducía al joven sacerdote a sentenciar que: "un pueblo materialista es un pueblo condenado á las agitaciones sociales, á las luchas de clases" ${ }^{15}$ En su perspectiva, este fenómeno del materialismo estaba presente en el país desde hacía ya tiempo (citaba como prueba de ello, las estadísticas de criminalidad, consumo de alcohol, nacimientos ilegítimos, etcétera) y había contribuido a preparar un terreno favorable para la acción de los agitadores.

En la asignación de responsabilidades, el sacerdote adjudicaba a las clases superiores el incumplimiento de su deber social. El lujo desenfrenado y las actitudes que exhibían cotidianamente habían promovido la emergencia de sentimientos de envidia e ira en la masa laboriosa. Además, observaba que no existía entre ellas un verdadero espíritu patronal, y quienes eran jefes de industria no se ocupaban de la suerte moral y material de "sus" obreros, ni tenían el "talento" para conceder por propia voluntad mejoras que redujeran la conflictividad.

Todo esto -que por sí solo bastaría para engendrar malestar social- se vio agravado por la acción de los agitadores. La propaganda ácrata llevaba varias décadas en la ciudad -de hecho, el autor decía poseer folletos publicados en 1898 por centros femeninos anarquistas-; diarios de esa misma tendencia, como La Protesta y otros periódicos antimilitaristas o gremiales, habían circulado hasta un par de semanas antes desarrollando el espíritu revolucionario y preparando los acontecimientos que tanto terror esparcirían. A ello, Franceschi sumaba la actitud del gobierno que admitía a sus referentes como portavoces de la clase trabajadora. Más aún, ubicaba como parte de las causas inmediatas la actitud de complacencia y debilidad que, en su perspectiva, había mostrado el gobierno radical. ${ }^{16}$

El autor del artículo reconocía, además, el impacto que habían tenido los factores económicos, por ejemplo, el encarecimiento del costo de vida y el retraso salarial producido durante la guerra. Llamaba la atención, asimismo, sobre la falta de sociedades cooperativas que podrían haber contenido o abaratado los precios de los artículos indispensables. Advertía, de este modo, que no debía obviarse la importancia del factor económico, aunque no lo consideraba un factor determinante. ${ }^{17}$ Por último, incluía la repercusión que habían tenido los acontecimientos revolucionarios en Europa al alimentar las esperanzas de trasformación social. Mientras el maximalismo estuvo confinado en Rusia, parecía demasiado lejano, pero su aparición en Occidente, tanto en Alemania como en Austria y durante las huelgas revolucionarias en Suiza, había hecho "brillar los ojos de los impacientes". Insistía en la responsabilidad de la prensa comercial, como así también de algunos conferencistas -como José Ingenieros-, por el acortamiento de esa distancia. Con esta conducta habían convertido al maximalismo en un asunto de moda y, como tal, tuvo sus admiradores, aun entre aquellos que "por su posición y cultura parecían los menos indicados para rendirle tributo". ${ }^{18}$

Según observaba Franceschi, el movimiento generado en Buenos Aires había sido preparado por ciertas organizaciones, pero no se le podía "atribuir una dirección única”. Fundamentalmente, había tomado parte, desde su perspectiva, el elemento "ruso" (al respecto aclaraba que dicho elemento, lejos de ser de raza eslava, estaba compuesto casi en su totalidad por hebreos, oriundos ya fuera de Rusia, Polonia, Austria o el 
Norte de Prusia, como bien lo demostraban los apellidos de los detenidos y de los muertos). Con esto daba credibilidad a los rumores sobre la existencia de comités secretos y su disposición de armas y dinero. Además, se habían involucrado numerosos individuos "contagiados por el revolucionarismo (sic)" al oír los tiros y los comentarios sobre batallones sublevados y triunfos ácratas en diversos puntos de la ciudad. De todos modos, entendía que la "revolución" no había sido fruto de una doctrina positiva y que, en cambio, habían participado socialistas de tinte avanzado, maximalistas propiamente dichos, anarquistas de diversos matices, y hombres sin programa alguno. Por eso, opinaba que la única denominación que los agrupaba a todos era "revolucionarios sociales".

Proponía como salida inmediata deportar a aquellos criminales y anarquistas que habían huido de su país de origen y que conspiraban aquí contra la constitución, las costumbres y las tradiciones argentinas. Aun así, aclaraba que no había que dejarse llevar por la xenofobia y que, por lo tanto, era preciso castigar también severamente a los argentinos que hubieran tomado parte en la revolución. En definitiva, veía como imprescindible desmontar la máquina de propaganda y organización revolucionaria; y anunciaba que el próximo intento sería "más peligroso aun, porque los dirigentes, con el fracaso pasado habían adquirido experiencia, palparon los defectos de su organización, y se preparar[rán]."19

\section{De UN Fin de AÑo tenso a la QUema de la iglesia Jesús SaCRAMENTAdo}

Entre mediados de 1918 y los sucesos de la Semana Trágica de enero de 1919, la conflictividad social y la violencia política se agudizaron. Desde la reactivación del comercio agroexportador, a fines de la I Guerra Mundial, los conflictos obreros habían crecido en número y organización (Ceruso, 2015), y en paralelo empezaba a conformarse una reacción patronal (Rapalo, 2012). Además, a comienzos de 1918, en Córdoba, se había iniciado el movimiento reformista universitario, al que el catolicismo había pasado de apoyar moderadamente a criticar con vehemencia y denuncias de infiltración maximalista (Mauro, 2018). El contexto internacional tampoco aportaba tranquilidad: fenómenos sociales similares al ocurrido en Buenos Aires se produjeron en países del Cono Sur (Lvovich, 2016), como también en otros más alejados como Alemania, cuyo levantamiento espartaquista se había producido solo unos días antes de la Semana Trágica argentina. A todo esto, que no era poco, se sumó la creciente preocupación en algunos sectores del catolicismo porteño por la movilización realizada con motivo de la fuga de la cárcel de Ushuaia del conocido anarquista Simón Radowitzky - preso por el atentado al jefe de la policía de la Capital, Ramón Falcón, en 1909-, la huelga de policías en la ciudad de Rosario a fines de 1918 (Maltaneres, 2010) y la presencia pública de una corriente de apoyo a la Revolución Rusa (Camarero, 2017; Díaz, 2019).

A fines de noviembre, podía leerse en El Pueblo un artículo con este tono:

Días hubo en los que estaba reservado á los ilusos y los temerosos el hablar del peligro anárquico. Hoy, la realidad es otra. Se ha dejado propagar la chispa revolucionaria y el maximalismo hoy no ha de ser importado: tenémoslo ya en casa" ${ }^{20}$ Sobresalía en la nota la preocupación por la complacencia de autoridades y de oposición política aún más que por la acción de los propagandistas de dichas ideas. En esta perspectiva, el ambiente de tolerancia reinante era asimilado a una "estúpida crianza de cuervos que habrán de sacarnos los ojos... ${ }^{21}$

Tan solo dos días más tarde, el acto organizado desde el anarquismo para protestar contra la detención de Radowizky y Barrera en Chile y su entrega a las autoridades argentinas reafirmó el diagnóstico de que el problema estaba "en casa": "El maximalismo ya no solo está en Buenos Aires en gestación. Anoche tuvimos una jornada maximalista completa, con discursos anárquicos de la más subida violencia, que eran escuchados pacientemente por los vigilantes" ${ }^{22}$ Para el diario católico, la oratoria expuesta en dicha jornada había sido "intolerable" y una "incitación abierta al delito". ${ }^{23}$ La prensa socialista confirmó que se había tratado de un acto numeroso y que la llegada de la noticia de que las autoridades chilenas habían entregado a los dos militantes dio pie a una improvisada movilización; esta fue impedida por la policía, y el tiroteo entre la policía 
y “muchos" individuos que estaban en la columna dejó como saldo varios heridos de bala. ${ }^{24}$ La prensa católica insistía en que las autoridades cometían un error al tolerar este tipo de acciones y formulaba su advertencia en los siguientes términos: "No se pongan valladares á la fiera y después será el llanto mujeril de quienes no saben hoy portarse como varones". ${ }^{25} \mathrm{La}$ actitud del gobierno radical, leída como debilidad de temperamento, era asociada con frecuencia a una falta de masculinidad. Finalmente, el artículo remarcaba que no se trataba de alarmismo: "[1]a tormenta la tenemos encima; el peligro es inminente...". ${ }^{26}$

Esa misma semana, otro artículo en El Pueblo alertaba, no sin manifestar cierta perplejidad, que aquella misma tarde se realizaría un nuevo mitin maximalista. ${ }^{27}$ Esta vez la convocatoria provenía del Partido Socialista Internacional (PSI); se habían fijado algunos carteles en los muros de la ciudad con grandes titulares que, en gruesos caracteres, invitaban al "Mitin maximalista". Según el artículo, en esos carteles se hacían incitaciones al desorden, a la anarquía y a la rebelión. La publicación insistía en la "miopía de las autoridades" y en el pronóstico de que "dentro de poco en Buenos Aires no se podrá vivir con más tranquilidad que en Moscú o en Petrogrado". ${ }^{28}$ Por otra parte, en la cobertura hecha por el diario del Partido Socialista se destacaba que la convocatoria "a un gran mitin maximalista" apenas había logrado movilizar "un par de millares" de personas, entre los que habían predominado anarquistas y maximalistas rusos. Se mencionaban corridas, petardos, palos y una importante presencia policial, que habría superado a la de los manifestantes. ${ }^{29}$

Ante la actitud pasiva que observaban en el gobierno, con el objetivo de dar su punto de vista sobre el maximalismo, un sector del catolicismo tomó la iniciativa de realizar una conferencia popular en la misma plaza. Recordemos que la realización de este tipo de actos no era nueva, sino que, por iniciativa del presbítero Dionisio Napal, se hacían con asiduidad desde $1916 .{ }^{30}$ El día previo a la conferencia, programada para el 8 de diciembre, un editorial de El Pueblo explicaba la importancia del evento indicando que el maximalismo estaba en todas partes -incluidas "las alturas"-. Dado que las autoridades políticas no hacían nada por evitar que el maximalismo se expandiera por "abajo", y que "todos" asistían impasibles al avance de la ola roja, la juventud cristiana y patriota de los centros de estudios y de acción social salían “á la palestra”. ${ }^{31}$

Organizado por la Federación de centros de acción y estudios sociales, adherida a los Círculos de Obreros, el acto contó con una concurrencia numerosa. En él se entonó el himno, se levantó la bandera nacional y el señor Juan B. Podestá y el presbítero Dionisio Napal disertaron sobre el “bolshevikismo” y la patria. Según $E l$ Pueblo, el evento había despertado interés "sobre todo después de los incidentes que días pasados alarmaron á la ciudad”. ${ }^{32}$ En la misma fuente se afirmaba que Napal se había referido al maximalismo; la revolución rusa, los apoyos que ésta recibía localmente de figuras como José Ingenieros; al lugar del "factor judío" en los movimientos revolucionarios del mundo; al oportunismo de los socialistas, etc. En el relato también se mencionaba la presencia de algunos "pobres exaltados, que inútilmente intentaron provocar desorden”, y la acción del auditorio, que "reprimió con inmediata y eficaz energía á algunos libertarios que se desesperaban por alterar el orden" ${ }^{33}$

Por su lado, en La Vanguardia, los socialistas agregaban que un ciudadano había pedido permiso para polemizar con Napal y que esto había sido concedido, pero que había sido atacado inmediatamente después de su intervención. Para ellos no era admisible que la tribuna pública fuese convertida "por obra de los frailes en un vaciadero de procacidades y ataque a las personas, como está sucediendo de un tiempo a esta parte, sin que la policía haga nada para evitarlo", y, extrañamente, indicaban que era indispensable hacer actuar a la policía antes de que "los excesos de lenguaje de la jauría clerical lleguen a provocar reacciones que no por ser violentas serían menos justificadas y legítimas" ${ }^{34}$ Por último, mientras El Pueblo valoró como positiva la acción policial, La Vanguardia resaltó que dicha intervención se llevó personas al azar, e incluyó el listado de las personas detenidas.

En las siguientes semanas hubo otras conferencias populares, no las relataremos a todas, pero sí nos interesa introducir aquí aquella que fue organizada por el Círculo de Obreros de Nueva Pompeya el 15 de diciembre en ese lejano barrio de la capital. El mitin tuvo lugar en avenida Sáenz y Traful, frente a la iglesia y a solo a 
algunas cuadras de Amancio Alcorta y Pepirí, donde ocurriría el choque que desencadenó la huelga general de enero de 1919. Al parecer, el público que asistió fue, como en los otros casos, numeroso, y contó con la presencia de una nutrida columna que quedaba subsumida, indistintamente, bajo la etiqueta de anarquista y socialista, o de "roja" o "ácrata". Conci, el primer orador, expuso sobre "el absurdo del socialismo" 35 y, cuando estaba terminando su discurso, "uno de los rojos más exaltados” agredió "por la espalda” a Napal. ${ }^{36}$ Entre uno y otro orador se produjo un violento entrevero, y el agresor habría huido perseguido por una cantidad de personas del público. También aquel día hubo algunas detenciones por parte de la policía.

Rápidamente, en respuesta a este hecho, la comisión directiva del Círculo de Obreros de Nueva Pompeya propuso la realización de una nueva conferencia pública para mostrar "la más enérgica y viril" de las protestas contra el ataque al sacerdote y orador católico por parte "de los elementos socialistas de la localidad". ${ }^{37}$ Así, convocado en defensa del "derecho de reunión", el acto se realizó el 5 de enero en Nueva Pompeya. ${ }^{38}$ La tribuna fue ocupada por Samuel Medrano, presidente del Círculo, Gustavo Franceschi y Dionisio Napal. Luego, la multitud formada por socios de los círculos de la ciudad y de otras organizaciones católicas marchó en compacta columna hacia el Parque Patricios. ${ }^{39}$ La Nación afirmaba que concurrió un "numeroso grupo de maximalistas" y que perturbó la reunión repetidas veces. También sostenía que, debido a la frecuencia de los incidentes (se arrojaban piedras contra los oradores), la policía de la sección 24 "cargó contra los promotores de los incidentes, disolviéndolos". ${ }^{40}$ Los “ácratas y rojos" habían preparado una especie de contramanifestación, y se improvisó una nueva tribuna en la que se señaló el temor que existía en los "antros rojos" de que se les fuera "el dominio fácil que habían adquirido en la masa, en veinte años de insidias impunemente propagadas"; se remarcaba, en consecuencia, la intolerancia y la desesperación de los "nuevos mazorqueros fracasados". ${ }^{41}$ En respuesta a quienes tiraban piedras desde el parque, salieron "grupos de jóvenes católicos, que en varios casos castigaron severa y ejemplarmente a los cobardes autores de esos atentados". ${ }^{42}$ También se realizó otro acto en el salón de los padres capuchinos de la iglesia Nuestra Sra. de Pompeya, en el que se responsabilizaba del atentado a "uno de los anónimos militantes de la mazorca socialista" ${ }^{43}$

De este modo, cierto clima de violencia y tensión precedió al incendio intencional del templo Jesús Sacramentado en el barrio de Almagro el día 9 de enero. Ese día, momentos antes de que el cortejo fúnebre pasara por delante del templo, una muchedumbre irrumpió y destrozó la iglesia Jesús Sacramentado y el asilo de niñas anexo dirigido por la Congregación de las Siervas de Jesús Sacramentado. El Pueblo indicó que un hombre (por aspecto, un obrero, y por su actitud, un ácrata) había ocupado una improvisada tribuna donde arengó a sus oyentes, que habrían sido alrededor de quinientos. En el momento en que iba llegando la columna principal, una banda de unos ochenta sujetos asaltó una armería en la calle Corrientes ubicada frente a la iglesia y luego con las armas robadas, el grupo saltó la verja de la iglesia. ${ }^{44}$ Según el diario católico, los atacantes eran jóvenes, en su mayoría rusos y catalanes; entre ellos se contaba casi una docena de mujeres, también de origen ruso, que, distinguidas por su procacidad, “con sus hechos pedían á gritos un par de pantalones" ${ }^{45}$ Un funcionario policial, Octavio Piñero, interpretaba el hecho como una prueba de ateísmo y de odio a la fe católica. Según su relato, y como indicó también la prensa católica, la dotación de policías y bomberos tardó en llegar; aunque se afirmaba que quienes estaban dentro del templo se hallaban prevenidos de lo que podía pasar y lograron ponerse a resguardo (1956, p. 45). Cuando las fuerzas de seguridad llegaron, se produjo un violento tiroteo cuyo saldo fue, nuevamente, varios muertos y heridos. ${ }^{46}$

La iglesia Jesús Sacramentado, ubicada en una zona en aquel momento alejada del centro de la ciudad, había sido construida con la colaboración económica de la familia Unzué y era reconocida por su elegancia y distinción. ${ }^{47}$ A pesar de tratarse de un orgullo para el catolicismo porteño y de ser dirigida por el padre Santiago Ussher, un sacerdote con amplia participación pública, vinculado a la obra de los Círculos de Obreros y especialmente próximo a monseñor De Andrea, no tenemos elementos para afirmar que su destrucción haya respondido a planes premeditados. Según el informe que Ussher dirigió al arzobispo, se 
perdió la mayor parte de los interiores de la iglesia y el mobiliario del colegio. También fueron consumidos por el fuego la biblioteca y los documentos del colegio desde su fundación en 1874; los archivos de las Hijas de María, del Apostolado de la Oración, de la Congregación de la doctrina y de la conferencia de señoras y del taller de señoritas vicentinas, asociaciones que hacían trabajos en el lugar.

De manera general, la quema de la iglesia fue leída como un crimen sacrílego y central, que constituía una muestra de la desprotección en que los había dejado el gobierno: "el hecho más saliente, más brutal, más criminal y repugnante cometido ayer, que subleva el ánimo, que prueba la falta de garantías que hay, la impotencia de la autoridad, su incapacidad para el gobierno, que debe consistir en prever". ${ }^{48}$ Como se podía prever, se comparó este hecho con la quema del colegio El Salvador en 1875 y se lo incluyó en una genealogía de actos propios de la Comuna de París (1971), de la Semana Roja de Barcelona (1909) y de la Rusia maximalista (1917). ${ }^{49}$ Debido a la inacción del gobierno, la incapacidad o imprevisión policial, sostuvieron que "la sociedad deberá defenderse por sus propios medios" ${ }^{50}$ Asimismo, entendían que ciertos conceptos sobre las "libertades de residencias, de asociación y de palabra hablada y escrita" debían necesariamente de ser revisados. ${ }^{51}$

A su vez, se mostraban impresionados por la actitud tomada por los principales diarios de la metrópoli. Decían que estos narraban el hecho

con inexplicable indiferencia, sin una sóla palabra de protesta contra el bárbaro atentado, perpetrado en pleno día, ante una multitud impregnada de los sentimientos más injustos y bajos, indignos de corazones humanos; hecho que significa no sólo una agresión á la conciencia y á la Religión del país, sinó al arte, al embellecimiento edilicio y al derecho de propiedad; derechos garantidos por la Constitución de la Nación. ${ }^{52}$

Interpretaban tal indiferencia como muestra de complicidad y una expresión lamentable de sus erróneas ideas acerca de la legalidad, la justicia y la libertad que podían conducir a las masas a excesos mayores aún.

Es en este contexto que la violencia se tematiza y se instala la cuestión de la autodefensa como problema para los católicos. La Revista Mariana demostraba su acompañamiento a las religiosas de Jesús Sacramentado indicando: "Jesús habrá exclamado (...) como exclamó ante las furiosas muchedumbres judías: ¡Perdonádles, Padre mío, porque no saben lo que hacen!". El argumento sostenido aquí era que la "venganza” admitida por el cristianismo y enseñada por Jesús no era otra que "sufrir y perdonar". 53

En cambio, un editorial de El Pueblo, que analizaba detenidamente la compasión cristiana -es decir, ese sentimiento de identificación con los males del prójimo-, argumentaba que esta no excluía la justicia, y, por lo tanto, admitía la represión y el escarmiento aleccionador. Más aún, en un conflicto, tampoco contemplaba solo a una de las partes, sino a todas ellas. Entonces, si bien la compasión cristiana apuntaba contra la crueldad sobre el victimario, al tener presentes a las víctimas debía "aceptar y acepta[ba] la represión y el escarmiento aleccionador" ${ }^{54}$ De manera general, y siguiendo la línea editorial señalada previamente, se declaraba la necesidad de que el país se previniese del "compasivismo", sentimiento que no debía confundirse con la compasión, considerada como positiva. ${ }^{55} \mathrm{El}$ "compasivismo", al ceñirse a quienes se les aplica una determinada pena, olvida los daños hechos y no tiene en cuenta que dejarlos "impunes" implicaría estimular su reproducción. Su presencia extendida ha malogrado la acción defensiva de la sociedad frente a los "peligros graves y reales que la han amenazado". ${ }^{56}$

De este contexto surgía, también, la necesidad de autodefensa. De alguna manera, la disputa con las izquierdas por ocupar el espacio físico y simbólico de la ciudad implicaba cierta confrontación física, "de cuerpo", que desde la conducción de los Círculos de Obreros era por lo menos aceptada. ${ }^{57}$ Así, por ejemplo, en la crónica del segundo acto que mencionamos, realizado en Pompeya, se resaltaba de manera positiva la reacción de los católicos, que, "resueltos y decididos", rechazaron y persiguieron "durante buen trecho a los rojos que, al primer amago de ataque, se dispersaron vergonzosamente...". ${ }^{58}$ Luego del episodio ocurrido en 
Nueva Pompeya con el padre Dionisio Napal, en la Junta de Gobierno de los Círculos de Obreros Católicos se propuso discutir un proyecto de cursos de box para que los socios pudieran defenderse de los ataques. ${ }^{59}$

Después del incendio del templo Jesús Sacramentado, en el diario El Pueblo se mencionó otro ataque a una iglesia de Avellaneda que había sido repelido inmediatamente. Ante este tipo de situaciones, se planteaba que era "menester que todas las instituciones católicas impuestas de la evidente falta de garantías (...) estén alerta, [y] tengan su vigilancia propia sin ahorro de armas ni de pólvora” ${ }^{60}$ Esto se sostenía, argumentalmente, en que la policía no daba abasto y en que, además, era patriótico contribuir a su acción. De manera que puede verse cierto corrimiento desde una posición ambivalente frente a la violencia hacia la afirmación del derecho de autodefensa de la fe, de la institución y de sus miembros; afirmación que, para algunos de ellos, se extendía a la defensa de la patria.

A su vez, este proceso empalmó con la organización de milicias cívicas que durante la semana de enero de 1919 acompañaron la represión estatal. En las primeras horas del día 10, civiles y policías liberaron sus sentimientos antisemitas y atacaron barrios, locales e instituciones de obreros de la colectividad. El general Dellepiane había permitido, no es claro si con la aprobación o no del presidente, el reparto de armamento a voluntarios civiles, como ya lo había hecho en 1910. El accionar de estos grupos se mantuvo hasta el 14 de enero, aunque quedó la impresión de que el estallido revolucionario estaba latente aún (McGee Deutsch, 2003, p. 86).

Paralelamente, en respaldo de este accionar, se hicieron distintas colectas para juntar fondos que serían destinados a las familias de los muertos o heridos por los huelguistas. La más importante fue la del Comité Pro-defensa del orden, dirigida por Domeq García ${ }^{61}$, creada para pedir la colaboración del gran comercio, de la industria, los exportadores, los terratenientes, los financieros, etcétera (McGee Deutsch, 2003, p. 87). El arzobispado colaboró activamente en la colecta organizada por este comité con la consigna de "socorrer los hogares de quienes han defendido el orden, la autoridad y también las iglesias y colegios católicos”. ${ }^{62}$

En continuidad con estas iniciativas, el 20 de enero se constituyó la Liga Patriótica Argentina (LPA); como referentes de la Iglesia Católica y el catolicismo, estuvieron presentes monseñor De Andrea y Piaggio (McGee Deutsch, 2003, p. 88). ${ }^{63}$ En un primer manifiesto, en el que se daban a conocer sus intenciones, la organización sostenía que el país contaba con "grandes leyes", pero que no se había asegurado un sistema de "sana" previsión social para amparar la invalidez, la enfermedad y la suerte de los "miles de obreros que han venido á buscar trabajo y bienestar entre nosotros". El crecimiento poblacional, comercial e industrial impulsado por un sentimiento materialista había descuidado el problema moral de hacer que la patria fuese tanto más alta y noble que el saldo favorable de la balanza comercial. ${ }^{64}$ A las fuerzas "organizadas para la destrucción” se proponía oponer fuerzas organizadas para el orden, la construcción y el progreso. Si bien entendían que las desigualdades sociales eran inherentes a la naturaleza humana, se buscaba que los favorecidos y los perjudicados comprendieran el beneficio de hacer dichas desigualdades "ménos violentas, más tolerables, más remediables". ${ }^{65}$

Como otras sociedades similares, el Círculo de Obreros de la Merced recibió el pedido de dar difusión al manifiesto citado. Este documento fue reproducido en el boletín parroquial de Nuestra Sra. de la Merced y, probablemente, difundido entre los trabajadores de la parroquia. La comisión directiva del Círculo indicaba haber "aceptado complacida la tarea de hacer conocer del elemento proletario existente, dentro de su radio de acción, el conceptuoso manifiesto de esa Honorable Junta, habiendo dado al efecto las órdenes correspondientes". ${ }^{66}$ Asimismo, auguraba a la nueva organización "el éxito más completo en la consecución de sus altos fines". ${ }^{67}$ Aun cuando no parece haber habido una resolución general de los Círculos de Obreros, este apoyo no se limitó solo al Círculo de la Merced.

Cuando en abril de ese año se terminó de definir tanto el programa como la forma institucional, y se eligieron las autoridades definitivas de la LPA, el Dr. Lorenzo Anadón integraba nuevamente la Junta Central Nacional. ${ }^{68}$ Un editorial de El Pueblo, que tomaba como propios los propósitos de la LPA, sostenía que las 
ideas expuestas por el doctor Carlés merecían la aprobación de todo el elemento sano del país y que, por eso, debían ser conocidas y meditadas por los lectores. De tal manera se podría observar "la concordancia existente entre ellas y las expuestas infinidad de veces en estas columnas”. ${ }^{69}$ Por esos días, la Federación de Propaganda, adherida a los Círculos de Obreros, planteaba la idea de la existencia de una esencia nacional, una actitud de rebeldía propia de los argentinos, que se había expresado en 1810 en forma de "noble protesta" contra la tiranía, el desorden, el antipatriotismo, la demagogia o la esclavitud. Continuaba diciendo que fue precisamente esa rebeldía argentina la que "se irguió contra el maximalismo amenazante á raíz de los sucesos de enero y fue la que provocó la fundación de la Liga Patriótica Argentina, en oposición á aquel y para realizar una nobilísima obra de argentinismo". Así, agregaban,

tócanos á nosotros constituir el dique inconmovible é inalterable que detenga el torrente avasallador que amenaza todo lo que haya de patriótico y religioso. Seamos el Pampero vivificador que borra esas nubes fatídicas y permita que brille, muy alto, el sol de la paz y justicia. ${ }^{70}$

Poco más de un mes más tarde, en el marco de los festejos patrios, la Liga participó de la organización de una importante manifestación, que tuvo una concurrencia estimada en 120.000 personas. Aunque los Círculos de Obreros parecían estar embarcados en la realización de su congreso social, algunos participaron de ella. Por ejemplo, el Círculo Nuestra Sra. de Buenos Aires, asentado a unas cuadras de donde ahora se ubica el monumento al Cid Campeador, invitaba a sus socios de la siguiente manera: “A la 1 p.m., incorporación á la manifestación patriótica, auspiciada por la Liga Patriótica Argentina y el consejo nacional de educación, á cuyo efecto en Gaona esquina Espinosa habrán tranvías especiales gratuitos". ${ }^{71}$

Ahora bien, estos vínculos y confluencias entre los Círculos de Obreros y la LPA no deben confundir acerca del hecho de que la acción institucional de los Círculos de Obreros fue por otro carril. A días de finalizada la huelga de enero, una delegación de estos últimos se reunió con el presidente de la nación y le llevó una nota en nombre de los millares de trabajadores que no habían podido intervenir en los últimos sucesos. ${ }^{72}$ No lo habían hecho debido a que las empresas particulares y las administraciones públicas habían prescindido de los elementos moderados. En ese sentido, señalaron que había llegado la hora de distribuir la responsabilidad de los horrores presenciados, y creían oportuno remarcar que el problema social no se resolvería sin el necesario aliento a los gremios sanos.

Asimismo, en la reunión del Consejo General, varios círculos propusieron la organización de un acto contra socialistas y ácratas, y en homenaje al Gral. Dellepiane. ${ }^{73}$ Por no tratarse del momento adecuado, De Andrea propuso postergar la iniciativa y realizarla junto con un congreso que reuniera a los católicos sociales. ${ }^{74}$ Efectivamente, a fines de mayo de 1919 se realizó el I Congreso de Católicos Sociales de América Latina, al que concurrieron numerosas delegaciones. ${ }^{75}$ Allí reafirmaron la necesidad y el derecho de la organización de los obreros a promocionar y defender sus intereses y condiciones profesionales, y esto debía darse sin la injerencia de los patrones ni de otras presiones extrañas. Así, se promovía el sindicalismo católico de base múltiple, que era visto como una vía sana de mejoramiento de la condición económica y social de los trabajadores, y se rechazaba "toda solidaridad con las organizaciones obreras de carácter socialista o anarquista, o del llamado sindicalismo de acción directa". ${ }^{76}$

La otra iniciativa relevante para contener la conflictividad social y encauzar los reclamos de los trabajadores, que surgió del seno del catolicismo, fue la Gran Colecta Nacional ${ }^{77}$, ideada por Miguel De Andrea, cuya concreción se consignó a la recientemente fundada Unión Popular Católica Argentina. ${ }^{78}$ Lo novedoso de esta colecta era su carácter nacional, ya que, como destacó Miranda Lida (2015), el término nacional tenía un doble sentido: por un lado, apelaba a todos los sectores, sin distinción de clases o pertenencia a grupos particulares y, al mismo tiempo, tenía un sentido territorial amplio, que no circunscribía la colecta al ámbito parroquial o diocesano (p. 86). La Iglesia se erguía como defensora de las masas populares, preservando el prestigio de la elite y canalizando la solidaridad social. Esta iniciativa tuvo lugar en dos etapas: a fines 
de septiembre con el pedido de recursos a grandes aportantes, y a fines de diciembre, con una fase más popular. Algunos autores destacaron el fuerte componente propagandístico que tuvo la colecta al haber intentado oponer a la "semana roja" de enero una "semana blanca" (Romero Carranza, 1956; Gerdes, 2016). Efectivamente, la colecta fue acompañada de una serie de conferencias y folletos en los que se trataban distintos puntos del programa social. ${ }^{79}$ Con todo, en función de las expectativas, sus alcances parecen haber sido limitados y en su mayoría los aportes provinieron de la elite.

\section{A MODO DE CIERRE}

En este trabajo hemos intentado reconstruir el posicionamiento y la intervención de los católicos sociales, con particular atención en aquel sector organizado en torno a los Círculos de Obreros, en la llamada Semana Trágica de Buenos Aires. Si bien el catolicismo militante se colocó en este contexto, como lo había hecho previamente, del lado de los defensores del orden, no pueden comprenderse algunas de las derivas ocurridas en los meses siguientes sin recorrer los momentos finales del año 1918 y las circunstancias producidas durante la huelga general de enero del 1919.

Esta huelga hizo fermentar distintas tendencias sociales presentes en la sociedad durante la inmediata posguerra. En aquel contexto de creciente polarización, diversos episodios, que tuvieron lugar en la ciudad desde los últimos meses de 1918, fueron representados en la prensa católica como una profecía largamente anunciada frente a la cual el gobierno radical no había estado a la altura. A lo largo del período abordado, los católicos denunciaron una y otra vez la falta de acción gubernamental para contener el avance del maximalismo en la ciudad. El tono de las críticas hacia el gobierno fue endureciéndose, y esto erosionó progresivamente el apoyo que se le había brindado en 1916, ya que manifestaron una fuerte desconfianza sobre su capacidad de controlar la situación.

Ante la falta de reacción de la política del gobierno, de la prensa y de la elite cultural, los Círculos de Obreros habían tomado la iniciativa de realizar acciones de propaganda específicamente contra el bolchevismo y sus expresiones locales. Las tensiones fueron en aumento y uno de sus referentes fue agredido. En este curso, se ha tratado de mostrar las modulaciones del discurso sobre el uso de la violencia. La quema de la iglesia Jesús Sacramentado marcó un hito, al rememorar episodios anticlericales previos que se articulaban con una tradición local y universal. A partir de entonces, El Pueblo intentó consolidar posiciones en torno a la aprobación de la violencia -que podía ser en determinadas circunstancias útil, necesaria y hasta conforme con la justicia cristiana- y sedimentar consensos sobre la necesidad de revisar algunos tópicos típicamente liberales como la libertad de prensa, el derecho de reunión o la libre inmigración, etc. Se aprecia aquí también una dinámica que observó Diego Mauro (2018) en su estudio sobre la reforma universitaria, la radicalización del conflicto universitario y su extensión, leída cada vez más en clave conspirativa y en un contexto de elevada conflictividad social, consolidaba en el catolicismo social las posiciones más refractarias, a la vez que debilitaba las perspectivas más moderadas o reformistas.

La convocatoria al laicado católico para que saliera a asistir a las fuerzas de seguridad en la defensa de los templos y de la religión empalmó con un proceso de organización de milicias cívicas acaudilladas por la marina, que acompañaron la represión estatal. En primer lugar, la diócesis se involucró en una colecta para ayudar a quienes habían defendido las instituciones y en los meses sucesivos fue visible el involucramiento de la Iglesia, como así también de figuras destacadas del llamado catolicismo social, en la conformación de la Liga Patriótica Argentina. Con la descripción del contexto en el cual se constituyó esta organización hemos procurado dar cuenta de la circulación de declaraciones, de la confluencia de posiciones y de las muestras de apoyo más amplias al interior de los Círculos de Obreros.

De todos modos, si retomamos parte de lo expresado por Gustavo Franceschi en su balance de la huelga general -el cual, a su vez, integraba muchos de los tópicos que habían sido planteados por el catolicismo desde los últimos años del siglo XIX-, observamos que esa relación no debe ser exagerada. En la perspectiva 
de Franceschi, con el control de la ciudad no debía darse por concluido el problema social y debían tomarse medidas urgentes para prevenir un próximo estallido. En el tratamiento de las causas profundas la religión católica estaba llamada a ocupar un rol central; por eso, el objetivo último de los católicos era la "recristianización" de la sociedad. Los propósitos de la Liga Patriótica Argentina, que pretendían trascender las medidas de corto plazo, se basaban en un desarrollo de una moral nacionalista y no avanzaban en el terreno religioso. Desde ese lugar interpretamos el apoyo amplio pero contenido, y la resolución del Consejo General de los Círculos de Obreros de convocar un congreso que reuniera a los católicos sociales de Suramérica; los intentos por consolidar el sindicalismo "sano", y, más adelante, la decisión de tomar parte en la Gran Colecta Nacional.

\section{Agradecimientos}

Una primera versión de este trabajo fue presentada en el III Coloquio Internacional sobre Violencia Política en el Siglo XX/ IV Jornadas de Trabajo de la Red de Estudios sobre Represión y Violencia Política (RER) realizadas en la ciudad de Rosario entre el 24 y el 26 de abril de 2019. Agradezco los comentarios de quienes participaron de la mesa "Derechas y violencia política". Asimismo, el trabajo se ha enriquecido con los aportes y observaciones de los evaluadores anónimos de la revista a quienes también les agradezco.

\section{FuenTES}

El Pueblo, diciembre de 1918; desde enero a fines de mayo de 1919.

La Nación, enero de 1919.

La Vanguardia, diciembre 1918.

Revista Mariana, de diciembre de 1918 a abril de 1919.

Revista Eclesiástica del Arzobispado de Buenos Aires, 1918 y 1919.

Actas de la Junta de Gobierno de los Círculos de Obreros, libro 5.

\section{REFERENCIAS}

Auza, N. (1987). Aciertos y fracasos sociales del catolicismo argentino. Grote y la estrategia social. Buenos Aires: Ed. Docencia- Don Bosco-Guadalupe.

Auza, N. (1987). Aciertos y fracasos sociales del catolicismo argentino. Mons. de Andrea realizaciones y conflictos. Buenos Aires: Ed. Docencia- Don Bosco-Guadalupe.

Auza, N. (1988). Aciertos y fracasos sociales del catolicismo argentino. El Proyecto Episcopal y lo social. Buenos Aires: Ed. Docencia- Don Bosco-Guadalupe.

Babini, N. (1956). Enero de 1919. Los hechos y los hombres de la "Semana Trágica". Buenos Aires: Servicio Editorial y Periodístico Argentino.

Ballent, A. (2014). La Iglesia y la vivienda popular. La Gran Colecta Nacional de 1919. En J. Liernur y A. Ballent (ed.), La casa y la multitud. Vivienda, politica y cultura en la Argentina moderna, pp. 215-236. Buenos Aires: Fondo de Cultura Económica.

Bilsky, E. (2011). La Semana Trágica. Buenos Aires: Ediciones RyR.

Camarero, H. (2017). Tiempos Rojos. El impacto de la Revolución rusa en la Argentina. Buenos Aires: Sudamericana.

Ceruso, D. (2015). La izquierda en la fábrica. La militancia obrera industrial en el lugar de trabajo, 1916-1943. Buenos Aires: Imago Mundi.

Di Stefano, R., y Zanatta, L. (2000). Historia de la Iglesia argentina. Desde la conquista hasta fines del siglo XX. Buenos Aires: Sudamericana. 
Di Stefano, R. (2010). Ovejas negras, Historia de los anticlericales argentinos. Buenos Aires: Sudamericana.

Díaz, H. (Coord.) (2019). Espionaje y revolución en el Rio de la Plata. Los archivos secretos de una red diplomática de persecución al maximalismo (1918-1919). Buenos Aires: Imago Mundo- Ediciones CEHTI.

Gerdes, T. (2016). La Semana Trágica y la perspectiva del catolicismo social sobre la cuestión social en el Rio de la Plata, 1880-1919, Villa María, Colección Poliedros. [Versión electrónica].

Godio, J. (1973). La Semana Trágica De Enero De 1919. Buenos Aires: Gránica Editor.

Lida, M. (2015). Historia del catolicismo en la argentina, entre el siglo XIX y el XX. Buenos Aires: Siglo XXI.

Lida, M. (2013). Monseñor Miguel De Andrea. Obispo y hombre de mundo (1877-1960). Buenos Aires: Edhasa.

Lvovich, D. (2003). Nacionalismo y antisemitismo en la Argentina. Buenos Aires: Javier Vergara Editor.

Lvovich, D. (2016). La Semana Trágica en clave transnacional. Influencias, repercusiones y circulaciones entre la Argentina, Brasil, Chile y Uruguay (1918-1919). En E. Bohoslavsky y J. F. Bertonha (comp.), Circule por la derecha. Percepciones, redes y contactos entre las derechas sudamericanas, 1917-1973. Los Polvorines: Ediciones de la UNGS.

Maltanares, A. (2010). Entre el diálogo y la represión. Estado y empleados públicos en conflicto. Rosario, 1918-1919”. En M. Bonaudo (dir.), Imaginarios y prácticas de un orden burgués. Rosario, 1850-1930 (pp. 117-137). Rosario: Prohistoria.

Martín, M. P. (2012). Iglesia católica, cuestión social y ciudadanía. Rosario Buenos Aires, 1892-1930 (Tesis doctoral inédita). Universidad Nacional de Rosario.

Mallimaci, F. (1992). El catolicismo argentino desde el liberalismo integral hasta la hegemonía militar. En AA.VV., 500 años de cristianismo en la Argentina (pp. 197-235). Buenos Aires: CEHILA, Nueva Tierra.

Mauro, D. (2010). De los templos a las calles. Catolicismo, sociedad y politica. Santa Fe, 1900-1937. Rosario: Prohistoria.

Mauro, D. (2015). El mutualismo católico en Argentina: el Círculo de Obreros de Rosario en la primera mitad del siglo XX. Historia Critica, 55, 181-205.

Mauro, D. (2018). Los católicos frente a la reforma universitaria (1917-1922). En D. Mauro y J. Zanca (Coords.), La reforma universitaria cuestionada. Rosario: Humanidades y Artes Ediciones -HyA ediciones.

McGee Deutsch, S. (2003). Contrarrevolución en la Argentina1900-1932: la Liga Patriótica Argentina. Quilmes: Ed. Universidad Nacional de Quilmes.

Piñero, O. (1956). Los orígenes y la trágica semana de Enero de 1919. Buenos Aires: Taller gráfico Bellsolá.

Rapalo, M. E. (2012). Patrones y obreros. La ofensiva de la clase propietaria. Buenos Aires: Siglo XXI.

Recalde, H. (1986). La Iglesia y la cuestión social. Buenos Aires: CEAL.

Rock, D. (2010). El radicalismo argentino, 1890-1930. Buenos Aires: Amorrortu Editores.

Romero Carranza, A. (1957). Itinerario de Monseñor De Andrea. Buenos Aires: Emecé Editores.

Sánchez Gamarra, A. (1997). Vida delpadre Grote. El apóstol de los trabajadores. Buenos Aires: Edición de la Federación de los Círculos de Obreros Católicos.

Silva, H. R. (2011). Días rojos, verano negro. Enero 1919, la semana trágica de Buenos Aires. Buenos Aires: Libro de Anarres.

Vigay, J. (2001). Historia del templo de Jesús Sacramentado. Buenos Aires: Junta Promotora de Estudios Históricos de los Barrios del Oeste.

Ussher, S. (1938). Maria Benita Arias: fundadora del Instituto de las Siervas de Jesús Sacramentado. Buenos Aires: El propagador cristiano.

\section{Notas}

1 Una primera versión de este trabajo fue presentada en el III Coloquio Internacional sobre Violencia Política en el Siglo XX/ IV Jornadas de Trabajo de la Red de Estudios sobre Represión y Violencia Política (RER) realizadas en la ciudad 
de Rosario entre el 24 y el 26 de abril de 2019. Agradezco los comentarios de quienes participaron de la mesa "Derechas y violencia política".

2 Huelga Talleres Vasena, Series históricas II, movimiento obrero año 1919, Ministerio del Interior, caja 31, carpeta 28, folio 7, Archivo Intermedio, Archivo General de la Nación.

3 "Los tiroteos últimos, fallecimiento de un cabo de policía", La Nación, 6/01/1919; "El cabo Vicente Chaves, sepelio de sus restos", La Nación, 7/01/1919.

4 “Huelga Vasena. Otro choque violento", El Pueblo, 6,7 y 8/01/1919; “Agitación obrera”, La Nación, 08/01/1919. Si bien las crónicas refieren un tiroteo extenso entre ambos bandos, los heridos de las fuerzas de seguridad tuvieron heridas menores y no realizadas con armas de fuego.

5 "Bajo el terror", El Pueblo, 10/01/1919.

6 Revista Eclesiástica del Arzobispado de Buenos Aires, IX (1909), 401.

7 Óp. Cit., 1000.

8 “El crimen anarquista del domingo", El Pueblo, 15 y 16/11/1909.

9 De los últimos auxilios religiosos de las víctimas participaron dos importantes figuras de la Iglesia argentina: monseñor Gregorio Romero y monseñor José Orzali y la participación institucional en el funeral fue importante. Al año siguiente, el arzobispo de Buenos Aires adhirió a la iniciativa de erigir un monumento para coronel Falcón y Sr. Lartigau, e inició una colecta de dinero en la diócesis. "El crimen anarquista del domingo", El Pueblo, 15 y 16/11/1909; "Efemérides", Revista Eclesiástica del Arzobispado de Buenos Aires, año IX, 1909, pág. 1002; "Efemérides”, Revista Eclesiástica del Arzobispado de Buenos Aires, año X,1910, p. 307.

10 "El crimen anarquista del domingo", El Pueblo, 15 y 16/11/1909. La cursiva es nuestra.

11 “Después de la tempestad", Revista Mariana, 20 (1919), 231.

12 Óp. Cit.

13 Óp. Cit.

14 "La revolución reciente. Su contenido moral y social", El Pueblo, 26/01/1919.

15 Óp. Cit.

16 Según David Rock, la Semana Trágica había hecho relucir la cuestión de la localización de poder político real del régimen político inaugurado en 1916 y los débiles soportes que tenían los cambios que había intentado instrumentar Hipólito Yrigoyen (2010, p. 170). Esto ha sido discutido o matizado por otros autores, entre ellos Sandra Mc Gee Deutsch.

17 "La revolución reciente. Su contenido moral y social”, El Pueblo, 26/01/1919.

18 Óp. Cit.

19 Óp. Cit.

20 "Deberes del momento. El peligro maximalista", El Pueblo, 28/11/1918.

21 Óp. Cit.

22 Según la versión policial, cuando la columna llegó al lugar donde se encontraba el piquete policial, del centro de la misma sonó un tiro y como resultado del enfrentamiento hubo varios heridos y 19 detenidos. "El maximalismo en Buenos Aires”, El Pueblo, 30/11/1918.

23 Óp. Cit.

24 "La fuga y la captura de Radowisky", La Vanguardia, 30/11/1918.

25 "El maximalismo en Buenos Aires", El Pueblo, 30/11/1918.

26 Óp. Cit.

27 "El mitin maximalista de hoy", El Pueblo, 1 de diciembre de 1918.

28 Óp. Cit.

29 "La manifestación de ayer. Tartufismo en acción", La Vanguardia, 2/12/1918.

30 Sobre estas conferencias ver (Auza 1987, pp. 85-106; Lida 2015, pp. 75-77).

31 "Significado de un mitin", El Pueblo, 8/12/1918.

32 "Las conferencias del domingo. En la Plaza del Congreso", El Pueblo, 9 y 10/12/1918.

33 Óp. Cit. Sobre el antisemitismo católico durante esta coyuntura ver (Lvovich, 2003 p.144-146 y 164-169).

34 "Procacidad clerical. Situación intolerable", La Vanguardia, 10/12/1918.

35 Militante laico de la comunidad salesiana involucrado activamente en la obra de los Círculos de Obreros, presidió luego la Confederación Profesional Argentina y los Círculos de Obreros.

36 "Las conferencias populares del domingo. En Nueva Pompeya-Grandioso Acto" El Pueblo, 16 y 17/12/1918.

37 Óp. Cit.

38 Después se haría un gran desfile hasta parque Patricios, donde hablarían Juan B. Podestá, José M. Samperio y Amadeo Barousse. "En defensa del derecho de reunión”, El Pueblo, 5/01/191919.

39 "Una jornada de gloria para la acción social católica", El Pueblo, 6, 7 y 8/01/1919.

40 "En el parque Patricios. Reunión tumultuosa”, La Nación, 6/01/1919.

41 Revista Eclesiástica del Arzobispado de Buenos Aires, XIX (1919), 112. 
42 Óp. Cit.

43 "En Nueva Pompeya. Homenaje al Pbro. Dr. Napal”, El Pueblo, 9/01/1919.

44 "Los atentados contra los templos", El Pueblo, 15/01/1919.

45 Óp. Cit. Otra versión sobre el origen del incidente afirma la presencia en la columna de un provocador (Silva 2011, p. 172).

46 Revista Eclesiástica del Arzobispado de Buenos Aires, XIX (1919), 117.

47 La vieja capilla había sido fundada por la madre Benita Arias en 1872 sobre la calle Yatay, a la vuelta de la Iglesia. Casi totalmente costeado por la familia Unzué, el nuevo templo se inauguró en mayo de 1904. La designación del padre Santiago Ussher a cargo de la misma fue sólo un año más tarde. Para más información sobre Jesús Sacramentado (Vigay, 2001) y respecto a Benita Arias (Ussher, 1938).

48 El Pueblo, 10/01/1919.

49 La violencia contra los templos católicos tuvo en el país distintos episodios antes y después de 1919. Sobre la larga tradición anticlerical, ver Di Stefano, 2010.

50 "Bajo el terror", El Pueblo, 10/01/1919.

51 “Horas negras”, El Pueblo, 11,12, 13 y 14/01/1919 (editorial fechada el 14).

52 Revista Mariana, Año XL, Núm. 19 (1919), 219. El subrayado es del original.

53 Óp. Cit.

54 "Prevención en tiempo", El Pueblo, 15 de enero de 1919.

55 Óp. Cit.

56 Óp. Cit.

57 Este mismo tono puede encontrarse en el relato de Alfredo Sánchez Gamarra (1997) sobre la vida de Federico Grote -el fundador de los Círculos de Obreros-, al recordar episodios tales como la fundación del Círculo de obreros de Saladillo, el atentado a Orzali, las columnas de movilizaciones a Luján, entre otros. Se trata, no obstante, de un libro escrito en el año 1949.

58 "Una jornada de gloria para la acción social católica”, El Pueblo, 6/01/1919.

59 Actas de la Junta de Gobierno de los Círculos de Obreros, libro 5, enero 1919.

60 "Los atentados contra los templos”, El Pueblo, 15/01/1919. En un tono similar, la Unión Democrática Cristiana habría sacado un manifiesto en que se denunciaba "como traidores a la causa de los obreros, a los agitadores profesionales que sólo han conseguido sembrar llanto, dolor y sangre” y agregaba que la Unión Democrática Cristiana llamaba a reflexión “a los verdaderos trabajadores para hacerles comprender que su fuerza está en la legalidad y en el orden, y que los malvados que se ensañan con débiles mujeres por el único hecho de ser monjas, nos encontrarán cruzados en su paso para rechazar las explosiones de su odio y su fanatismo" (Romero Carranza, 1957, p. 131).

61 Era contraalmirante de la marina, el organizador de la represión civil y central en la constitución de la LPA a la cual presidia provisoriamente. En la comisión también participaba Atilio Dell ' Oro Maini, católico que dirigía la Asociación del Trabajo.

62 "Pro defensores del Orden. - Circular del arzobispado", En <Noticias de actualidad〉, Revista Mariana, Núm. 21 (1919), pág. 252.

63 Ya en la Junta Directiva provisional de la LPA había dos importantes figuras vinculadas a los Círculos de Obreros: Lorenzo Anadón (presidía la Junta de Gobierno) y Miguel de Andrea (ex director espiritual de los Círculos y una figura muy influyente en el arzobispado).

64 “Liga patriótica argentina” reproducido en Revista Mariana, 28 (1919), p. 336.

65 Óp. Cit.

66 "La Liga Patriótica Argentina y el Círculo de la Merced”, Revista Mariana, 34 (1919), 410; "Liga Patriótica Argentina. Adhesión del C. de Obreros de la Merced" El Pueblo, 5/04/1919.

67 Firmado por Enrique Udaondo, presidente y J. Pablo Días Gómez, secretario. "La Liga Patriótica Argentina y el Círculo de la Merced", Revista Mariana, 34 (1919), 410.

68 "Liga Patriótica Argentina. Nuevas autoridades", El Pueblo, 7 y 8/04/1919.

69 “Argentinismo", El Pueblo, 10/04/1919.

70 “Círculos de Obreros. Federación de Propaganda”, El Pueblo, 9/10/1919.

71 “Círculos de Obreros”, El Pueblo, 22/05/1919.

72 "Los círculos de obreros ante el presidente de la república”, Revista Mariana, Núm. 22 (1919), 263.

73 Actas Junta de Gobierno de los Círculos de Obreros, Libro 5, enero 1919.

74 "Consejo general de los círculos de obreros", El Pueblo, 22/01/1919.

75 Elías Niklison. “Acción social católica obrera”. En Boletín del Departamento Nacional del Trabajo. Núm. 46 (1920), 111-113.

76 Óp. Cit., pág. 116. Asimismo, como ha indicado Thomas Gerdes, el periódico de la Liga Social Argentina, que también celebró la fundación de la LPA, advertía que no se debía proceder siempre del lado del capital contra los trabajadores 
y que tampoco se debía cometer el error de confundir el "maximalismo", que era "la aspiración de establecer un orden socioeconómico comunista” con las justas exigencias de los trabajadores (2012, p. 303).

77 Aproximadamente la mitad de lo recaudado fue utilizada en la construcción de viviendas obreras (Ballent, 2014 p. 230). Si bien analizar el alcance de la Gran Colecta Nacional excede por mucho los objetivos de este escrito, se debe indicar que Thomas Gerdes sostiene que se trató de una importante iniciativa del Arzobispado -delegada en la UPCA y en de Andrea- que no ha sido adecuadamente destacada por la bibliografía debido al menor interés que tuvo el principal historiador católico sobre el catolicismo social -Néstor T. Auza- por destacar la obra de Mons. De Andrea. A su vez, Gerdes deja ver que entre los aportantes de la colecta hubo muchos miembros de la LPA.

78 Proceso de centralización de las organizaciones católicas promovida por el episcopado, que seguía el modelo del laicado italiano. Con la aparición de UPCA se disolvieron la Liga Social Argentina y la Unión Democrática Cristiana, y la acción sindical -centrada en la Confederación Profesional Argentina- pasó de la órbita de los Círculos a depender de esta.

79 "Los compromisos de la Gran Colecta Nacional. Cómo se cumplen", impreso en los talleres gráficos de Luis Gotelli en 1923. Folleto con firma de Santiago Ussher disponible en la Biblioteca Argentina de Rosario. 